\title{
Diallyl sulfide induces cell cycle arrest and apoptosis in HeLa human cervical cancer cells through the p53, caspase- and mitochondria-dependent pathways
}

\author{
PING-PING WU ${ }^{1 *}$, HUI-WEN CHUNG ${ }^{2 *}$, KUO-CHING LIU ${ }^{2}$, RICK SAI-CHUEN WU ${ }^{7}$, \\ JAI-SING YANG $^{5}$, NOU-YING TANG ${ }^{3}$, CHYI LO $^{3,4}$, TE-CHUN HSIA ${ }^{3,8}$, \\ CHIEN-CHIH YU ${ }^{1}$, FU-SHIN CHUEH ${ }^{10}$, SONG-SHEI LIN ${ }^{9}$ and JING-GUNG CHUNG ${ }^{6,11}$
}

\begin{abstract}
Schools of ${ }^{1}$ Pharmacy, ${ }^{2}$ Medical Laboratory Science and Biotechnology, ${ }^{3}$ Chinese Medicine and ${ }^{4}$ Nursing,
Departments of ${ }^{5}$ Pharmacology and ${ }^{6}$ Biological Science and Technology, China Medical University; Departments of ${ }^{7}$ Anesthesiology, ${ }^{8}$ Internal Medicine, China Medical University Hospital, Taichung 404;

${ }^{9}$ Department of Medical Imaging and Radiological Science, Central Taiwan University of Science and Technology, Taichung 406; Departments of ${ }^{10}$ Health and Nutrition Biotechnology, and ${ }^{11}$ Biotechnology, Asia University, Taichung, Taiwan, R.O.C.
\end{abstract}

Received December 29, 2010; Accepted February 21, 2011

DOI: $10.3892 /$ ijo.2011.973

\begin{abstract}
Diallyl sulfide (DAS), one of the main active constituents of garlic, causes growth inhibition of cancer cells in vitro and promotes immune responses in vivo in experimental settings. However, its effects on the induction of cell cycle and apoptosis in human cervical cancer cells are still unclear. The aims of this study were to explore the anti-cancer effects of DAS in HeLa human cervical cancer cells and to investigate the underlying mechanisms in vitro. Cytotoxicity and apoptosis in HeLa human cervical cancer cells were examined by the morphological changes, viability assay, 4',6-Diamidino-2-phenylindole dihydrochloride (DAPI) staining, comet assay, Western blotting and confocal microscopy examination. The results showed that DAS treatment for 24-72 $\mathrm{h}$ resulted in a marked decrease in cell viability time- and dose-dependently. Flow cytometric analysis showed that a 48-h treatment of $75 \mu \mathrm{M}$ DAS induced G0/G1 cell cycle arrest and sub-G1 phase (apoptosis) in HeLa cells. Typical apoptotic nucleus alterations were observed by fluorescence microscopy in HeLa cells after exposure to DAS using DAPI staining. Cells treated with different concentrations of DAS also showed changes typical of apoptosis such as morphological changes, DNA damage and fragmentation, dysfunction of
\end{abstract}

Correspondence to: Professor Jing-Gung Chung, Department of Biological Science and Technology, China Medical University, No. 91, Hsueh-Shih Road, Taichung 40402, Taiwan, R.O.C.

E-mail: jgchung@mail.cmu.edu.tw

*Contributed equally

Key words: diallyl sulfide, cell cycle arrest, apoptosis, mitochondria, caspase-3, human cervical cancer HeLa cells mitochondria, cytochrome $c$ release and increased expression of pro-caspase-3 and -9. DAS also promoted the release of AIF and Endo G from mitochondria in HeLa cells. In conclusion, DAS induced G0/G1 cell cycle arrest and apoptosis in HeLa cells through caspase- and mitochondria and p53 pathways providing further understanding of the molecular mechanisms of DAS action in cervical cancer. This study, therefore, revealed that DAS significantly inhibits the growth and induces apoptosis of human cervical cancer HeLa cells in vitro.

\section{Introduction}

Cervical cancer is one of major causes of death among women in most developed countries. In Taiwan, cervical cancer is the sixth leading cause of cancer mortality, about 6.0 persons per 100 thousand die annually from cervical cancer based on the reports from the Department of Health, Executive Yuan, ROC (Taiwan) in year 2008. Apoptosis is a programmed cell death accompanied by chromatin condensation, membrane blebbing, cell shrinkage, apoptotic body and DNA fragmentation (ladder) $(1,2)$. It is known that several factors lead to the induction of apoptosis such as the initiation by oxidative stress, then activation of caspases that are involved in the induction of apoptosis (cell death) (3). Therefore, a good strategy for killing cancer cells is through the induction of apoptosis of cancer cells.

Substantial evidence has demonstrated that some components from natural plants can suppress tumor development and decrease the incidence and severity of cancer in human (4). Garlic (Allium sativum L.), is widely used as foodstuff and medicine throughout the recorded history (5). Based on epidemiologic, clinical, and laboratory studies we have indicated that Allium vegetables and/or their constituents contain biological activities that stimulate immune function 
$(6,7)$, reduce the risk of cardiovascular diseases (8-11), change blood glucose level $(12,13)$ anti-microbial, viral and fungal infections (14-16), anti-aging effects $(17,18)$, anti-cancer function (19-21) and anti-tumorigenesis effects (22). Increasing evidences has suggested that the mechanism of anti-cancer action of garlic compounds may involve modulation of signal transduction pathways (23).

Diallyl sulfide (DAS), one of the component of garlic, has been reported to act as a potential chemopreventive function for many human cancer such as colon, lung, and skin (24). In our earlier studies, DAS inhibited the $\mathrm{N}$-acetyltransferase activity in bacteria $(25,26)$, human colon cancer cells $(27)$ and bladder cancer cells (28), and inhibits murine WEHI-3 leukemia cells in BALB/c mice in vitro and in vivo (29). However, the mechanistic role of DAS-mediated apoptosis in human cervical cancer cells, especially the role of ER stress, caspases, and mitochondria in the induction of apoptosis remains limited. In this study, we present evidence that DAS generated ROS, induced cell cycle arrest and apoptosis in HeLa cells through caspase- 3 and mitochondria-dependent pathways.

\section{Materials and methods}

Chemicals and reagents. RPMI-1640 medium, fetal calf serum (FCS), trypan-blue, penicillin G and streptomycin were obtained from Invitrogen Corp. (Carlsbad, CA). Dimethylsulfoxide (DMSO), ribonuclease (RNase), and propidium iodide (PI) were purchased from Sigma-Aldrich (St. Louis, MO). All antibodies were obtained from Santa Cruz Biotechnology (Santa Cruz, CA) or from BD Pharmingen (San Diego, CA). The secondary antibody of peroxidase-conjugated was purchased from Pierce (Rockford, IL). Western blotting detection kit was obtained from Amersham Life Science (Buckinghamshire, UK).

Cell culture. Human cervical cancer HeLa cells were obtained from the Food Industry Research and Development Institute (Hsinchu, Taiwan). Cells were maintained in RPMI-1640 medium supplemented with $10 \%$ fetal calf serum, $2 \mathrm{mM}$ glutamine, and antibiotics $(100 \mathrm{U} / \mathrm{ml}$ penicillin and $100 \mu \mathrm{g} / \mathrm{ml}$ streptomycin) at $37^{\circ} \mathrm{C}$ in a humidified atmosphere of $5 \% \mathrm{CO}_{2}$.

Morphological changes examined by a phase-contrast microscopic study. HeLa cells $\left(2 \times 10^{5}\right.$ cells/well) were maintained in 12 -well plates for $24 \mathrm{~h}$ and treated with various doses of DAS for $24 \mathrm{~h}$. Morphological changes of cells from each treatment were observed and photographed under a phase-contrast microscope $(30,31)$.

Cell viability, cell cycle and apoptosis by PI staining were examined by flow cytometric assay. After cells were treated with or without DAS for various time-periods, cells were harvested by centrifugation for determining the percentage of viability by staining with PI $(5 \mu \mathrm{g} / \mathrm{ml})$ and were analyzed by flow cytometry (Becton-Dickinson, San Jose, CA, USA) as previously described $(30,31)$. For cell cycle distribution and apoptosis determinations, the adherent cells were washed with PBS, and $300 \mu \mathrm{l}$ trypsin was added for $5 \mathrm{~min}$ at room temperature to detect the cells and harvested the cells by centrifugation. Cells were fixed gently in $70 \%$ ethanol at $4{ }^{\circ} \mathrm{C}$ overnight and then re-suspended in PBS containing $40 \mu \mathrm{g} / \mathrm{ml}$ PI and $0.1 \mathrm{mg} / \mathrm{ml}$ RNase and $0.1 \%$ Triton X-100 in a dark room for $30 \mathrm{~min}$ at $37^{\circ} \mathrm{C}$. Cells were analyzed with a flow cytometer $(32,33)$. The results were analyzed by Mod Fit LT 3.0 software.

DAPI staining and Comet assay for DNA damage. For DNA condensation studies, exponentially growing HeLa cells were cultured at a density of $2 \times 10^{5}$ cells/well onto 12 -well culture plates and treated with various concentrations of DAS for $24 \mathrm{~h}$. The cells were then washed with PBS, permeabilized in $0.1 \%$ Triton X-100 for $10 \mathrm{~min}$ at room temperature, stained with 4'-6-diamidino-2-phenylindole dihydrochloride (DAPI, $2 \mu \mathrm{g} / \mathrm{ml}$, Sigma) for $15 \mathrm{~min}$ at $37^{\circ} \mathrm{C}$, and observed and photographed by fluorescence microscopy. The alkaline comet assay was performed basically as described previously with minor modifications $(31,32)$. Several slides were prepared for each treatment and control. Fifty randomly selected cells were blindly examined for each triplicate slide with the same scorer at magnification of $\mathrm{x} 400$. Then cells with comet tail were photographed and by using fluorescence microscopy as described previously $(32,33)$. Comet tail length (TL), measured from the estimated centre of the cell, was evaluated for each cell as DNA damage parameter.

Flow cytometric assay for the production of $\mathrm{Ca}^{2+}$ and the level of mitochondrial membrane potential. To examine the $\mathrm{Ca}^{2+}$ and mitochondrial membrane potential in DAS induced apoptosis, HeLa cells were maintained in 12-well culture plates and treated with $75 \mu \mathrm{M}$ of DAS for $0,0.5,1$ or $2 \mathrm{~h}$ before being harvested, washed twice with PBS, and re-suspended in $500 \mu \mathrm{l}$ of calcium probe Indo 1/AM or $500 \mu \mathrm{l}$ of the mitochondrial membrane potential indicator 3, 3'-dihexyloxacarbocyanine iodide $\left(\mathrm{DiOC}_{6}\right)$, respectively. The samples were incubated at $37^{\circ} \mathrm{C}$ for $30 \mathrm{~min}$ to detect changes in $\mathrm{ROS}, \mathrm{Ca}^{2+}$ levels and mitochondrial membrane potential by flow cytometry as previously described (32-34).

Western blot analysis. HeLa cells $\left(5 \times 10^{6}\right)$ were treated with $75 \mu \mathrm{M}$ DAS for $0,6,12,24,48$ and $72 \mathrm{~h}$. Cells were harvested and the total cellular proteins were extracted by incubating the cells in the lysis buffer [50 mM Tris- $\mathrm{HCl}(\mathrm{pH} 7.5), 100 \mathrm{mM}$ $\mathrm{NaCl}, 0.5 \%$ (v/v) Triton X-100, 1 mM EDTA, $2.5 \mathrm{mM}$ sodium orthovanadate, $10 \mu \mathrm{l} / \mathrm{ml}$ protease inhibitor cocktail, $1 \mathrm{mM}$ PMSF]. The total protein concentrations in the cell lysates from each treatment were determined by Bio-Rad assay according to the manufacturer's protocols. All samples were loaded with equal amounts of protein into the SDS-PAGE in $10 \%$ tricine gels. At the end of electrophoresis, the proteins in the gels were transferred to a nitrocellulose membrane which was blocked with 5\% non-fat milk in TBST buffer for $1 \mathrm{~h}$ then incubated with primary antibodies (anti- $\beta$-actin, -CDK6, -CDK2, -cyclin D, -cyclin E, -p53, -Fas, -FasL, -caspase-8, -Bax, -cytochrome $c$, -Apaf-1, -Bid, -caspase-9, -caspase-3, -AIF and -Endo G) at 1:1000 dilution in 5\% non-fat milk overnight at $4^{\circ} \mathrm{C}$, then washed twice, followed by secondary antibodies (rabbit anti-IgG) conjugated with horseradish peroxidase at 1:1000 dilution for $1 \mathrm{~h}$ at room temperature. After extensive washing with TBST, protein bands were 
A

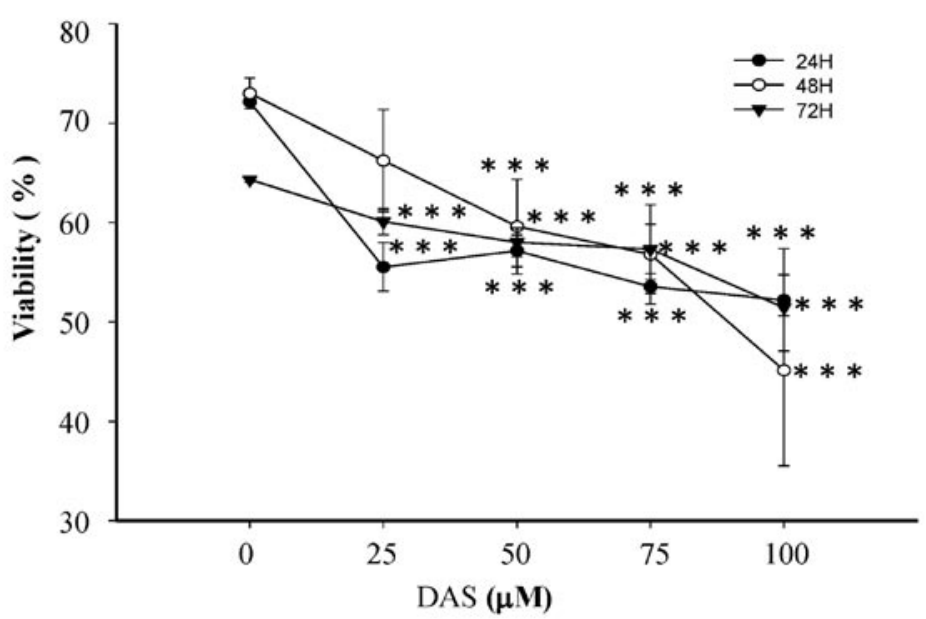

B
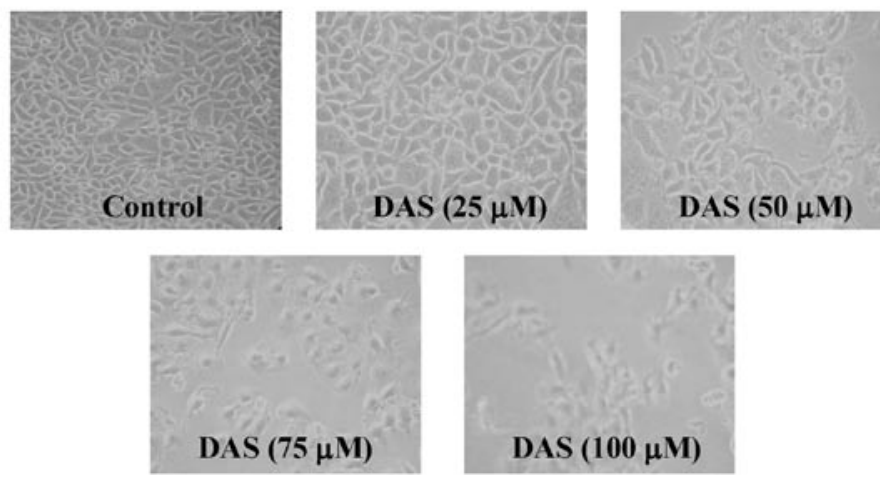

Figure 1. DAS effects on cell viability and morphology in HeLa cells. Cells were cultured with various concentrations of DAS for 24,48 and $72 \mathrm{~h}$ and were examined for viability (A) and morphological changes (B). To assess the percentage of total viable cells, the cells were counted by PI-incorporation and flow cytometric analysis, and for morphological changes phase contrast microscope was used as described in Materials and methods. Each point is the mean \pm SD of three experiments. ${ }^{* * * *} \mathrm{P}<0.001$.

visualized by the enhanced chemiluminescence reagent (SuperSignal West Pico Chemiluminescent Substrate; Pierce, Rockford, IL, USA). The expression ratio of experimental and control was calculated according to the reference band of $\beta$-actin $(32,34)$.

Confocal laser scanning microscopy. The preparations of samples for examining the translocation of Endo $G$ were performed as described $(31,35)$. HeLa cells $\left(5 \times 10^{4}\right.$ cells/well $)$ were maintained on 4-well chamber slides and were treated with $75 \mu \mathrm{M}$ DAS for $24 \mathrm{~h}$. All samples (cells from each treatment) were fixed in $4 \%$ formaldehyde in PBS for $15 \mathrm{~min}$ then were permeabilized with $0.3 \%$ Triton X-100 in PBS for $1 \mathrm{~h}$ with blocking of non-specific binding sites using 2\% BSA as described previously $(31,36)$. The primary antibody (antiEndo G) (1:100 dilution) (green fluorescence) was added to the fixed cells for primary staining overnight then followed by the exposure of secondary antibody (FITC-conjugated goat anti-mouse $\operatorname{IgG}$ at 1:100 dilution) and then stained with PI (red fluorescence). Then cells were examined and photographed by using a Leica TCS SP2 Confocal Spectral microscope.

Microarray assay. The total RNA was extracted from HeLa cells treated with or without $75 \mu \mathrm{M}$ DAS for $24 \mathrm{~h}$ by using
Qiagen RNeasy Mini Kit. The total RNA was used for cDNA synthesis and labeling, then microarray hybridization. Flourlabeled cDNA hybridized their complements on the chip, and the resulting localized concentrations of fluorescent molecules were detected and quantitated (Asia BioInnovations Corp.). Resulting data were analysed by using Expression Console software (Affymetrix) with default RMA parameters. Genes regulated by DAS were determined with a 2-fold change (37).

Statistical analysis. Significance of the mean values between intergroup was obtained using Student's t-test. Data are expressed as the mean \pm SD. $p \leq 0.05$ was considered significant.

\section{Results}

DAS inhibited the growth of HeLa cells. To assess the antitumor potential of DAS in human cervical cancer cells, HeLa cells were treated with $0,25,50,75$, and $100 \mu \mathrm{M}$ of DAS, and cell viability was evaluated by flow cytomteric assay. When cells were treated with DAS, it significantly decreased the percentage of viable HeLa cells in a dose-dependent manner (Fig. 1A). After cells were treated with DAS for $24 \mathrm{~h}$ they were examined for cell morphology by phase-contrast microscopy. The results revealed that some cells became round, blunt and 
$\mathbf{A}$
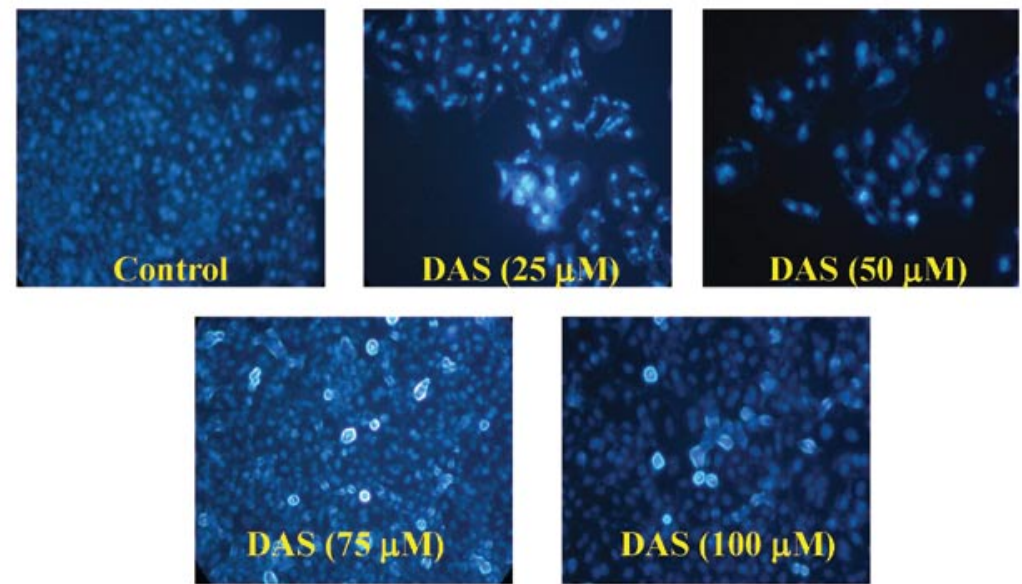

B
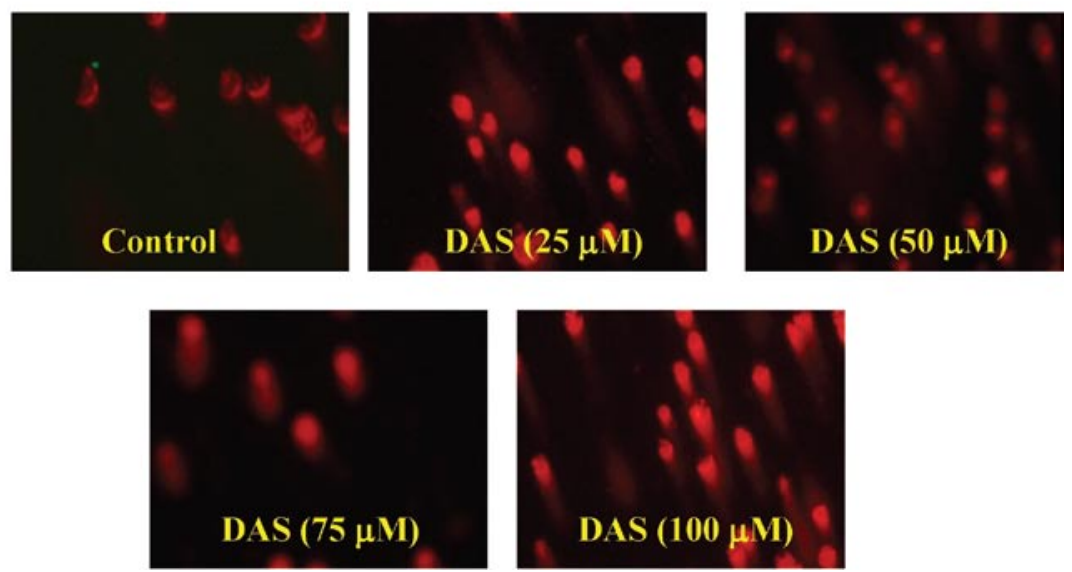

Figure 2. DAS-induced apoptosis and DNA damage in HeLa cells. Cells were treated with various concentrations of DAS for $24 \mathrm{~h}$ and apoptosis was determined by DAPI staining (A), DNA damage was measure by Comet assay (B) and DNA fragmentation was examined by DNA gel electrophoresis, and photographed by fluorescence microscopy (x200) as described in Materials and methods.

smaller in size, furthermore, cells became detached and suspended in the medium, especially with 50-100 $\mu \mathrm{M}$ DAS. The control group cells maintained their regular morphology and grew fully in patches and confluently (Fig. 1B).

DAS induces DNA damage in HeLa cells. To assess whether or not DAS could induce apoptosis and DNA damage in HeLa cells, DNA damage was assessed by DAPI staining and Comet assay, respectively. The present study found that DAS induced dose-dependent apoptosis in HeLa cells as determined by the DAPI nuclear staining assay (Fig. 2A). DNA strand cleavage induced by DAS was also observed in HeLa cells (Fig. 2B) which suggested that DAS treatment could induce cytotoxicity in HeLa cells.

Induction of cell cycle arrest by DAS. In order to determine whether DAS had any effect on progression through the cell cycle, HeLa cells were treated with $75 \mu \mathrm{M}$ of DAS for $0,6,12$, 24, 48 and 72 h. As depicted in Fig. 3A, DAS significantly increased in the $\mathrm{G} 0 / \mathrm{G} 1$ cell population, accompanied by a decrease in G2/M and S cell populations and the effects were time-dependent. To assess whether DAS induced G0/G1 phase arrest through the inhibition of check-point protein, cells were harvested after exposure to $75 \mu \mathrm{M}$ of DAS then were assayed by Western blotting (Fig. 3B). DAS treatment for $24 \mathrm{~h}$ resulted in an up-regulation of p53 and CDK6 in HeLa cells. In addition, DAS down-regulated cyclin D and $\mathrm{E}$ protein levels which is a hallmark for G0/G1 accumulation.

DAS decreases the levels of mitochondrial membrane potential and increases the levels of $\mathrm{Ca}^{2+}$ in HeLa cells. To assess whether DAS induced cell death through the dysfunction, cells were harvested after exposure to DAS then assayed by flow cytometry (Fig. 4). DAS treatment in HeLa cells at $75 \mu \mathrm{M}$ led to decrease the levels of mitochondrial membrane potential (Fig. 4A) at 1 and $2 \mathrm{~h}$ treatment. Fig. 4B also shows that DAS promoted the levels of $\mathrm{Ca}^{2+}$ in HeLa cells and these effects were time-dependent.

DAS affects apoptosis-associated protein levels in HeLa cells. To examine the role of apoptotic associate proteins in HeLa cells after exposure to DAS Western blotting was used (Fig. 5). Results indicated that DAS promoted the levels of Fas, FasL and caspase-8 (Fig. 5A), Bax, cytochrome c, Apaf-1, Bid, caspase-9 and -3 (Fig. 5B) which may be through the induction of apoptosis. Fas and FasL were promoted which indicated that DAS may be via the connection with Fas then activation of caspase- 8 and -3 leading to apoptosis. These 
A

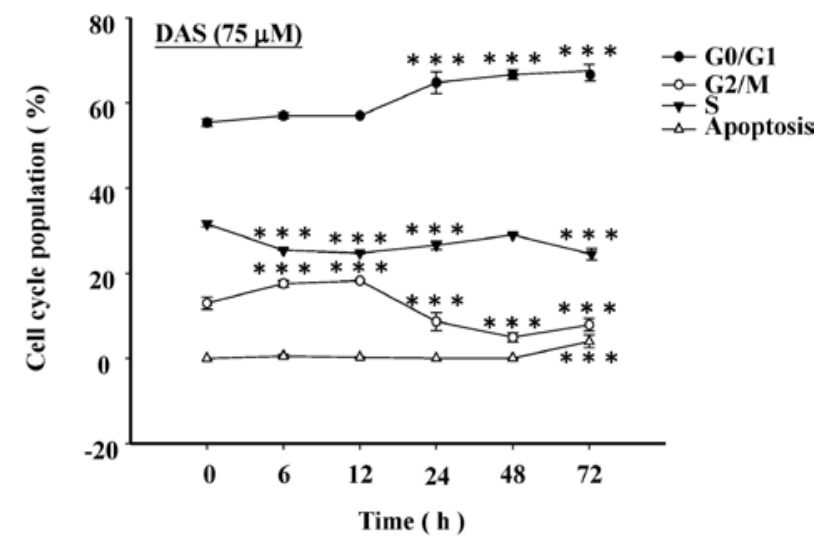

B

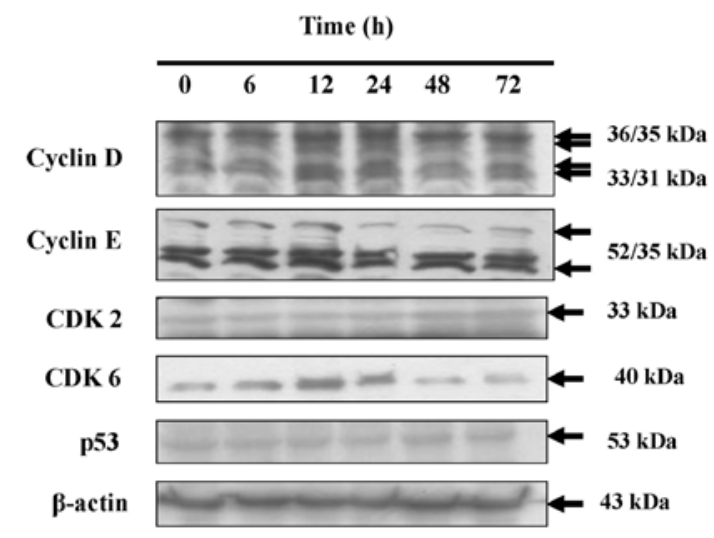

Figure 3. DAS effects on the cell cycle arrest and associated protein levels in HeLa cells. Cells were treated with various concentrations of DAS for indicated time periods, and the percentage of each phase and sub-G1 phase (apoptosis) (A) were measured by flow cytometry, as described in Materials and methods. The G0/G1 arrest associated protein levels were examined by Western blotting (B) as described in Materials and methods. Data represent the mean \pm SD of three experiments. ${ }^{* * *} \mathrm{P}<0.001$.

results suggest that DAS induces HeLa cell apoptosis, at least partly, through up-regulation of pro-apoptotic Bax, resulting in dysfunction of mitochondria and activation of caspase- 3 and -9 .

DAS affects Endo $G$ at protein level and translocation in $\mathrm{HeL}$ a cells. To investigate the mechanism underlying apoptosis induced by DAS, we tested the effect of this compound on Endo G and AIF levels released from mitochondria. Fig. 4A shows that DAS decreased the levels of mitochondrial membrane potential. DAS induced apoptosis may also be through the mitochondrial-dependent pathway (Fig. 5B) and DAS promoted the levels of AIF and Endo G (Fig. 6A) showing Endo $\mathrm{G}$ release from mitochondria by Confocal laser scanning microscopy analysis (Fig. 6B).

DNA microarray analysis for DAS-induced cell cycle arrest and apoptosis in HeLa cells. DNA microarray analysis was performed to examine the gene expression profile in the DAS-treated HeLa cells. HeLa cells were treated with DAS for $12 \mathrm{~h}$. The microarray analysis showed that 28 genes (17 genes, up-regulated; 11 genes, down-regulated) were expressed
A
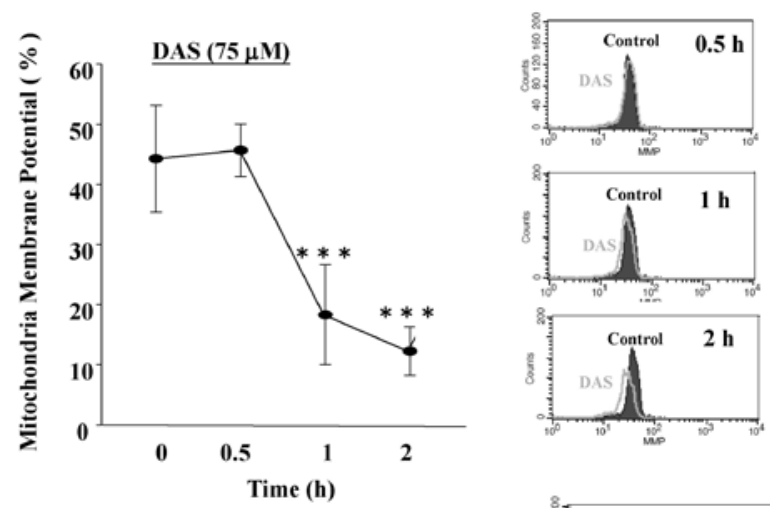

B

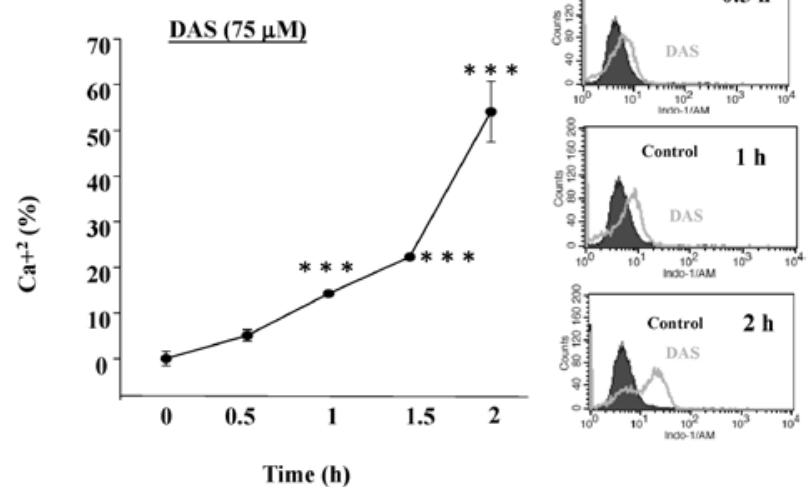

Figure 4. DAS decreased the levels of mitochondria membrane potential $(\Delta \Psi \mathrm{m})$ and induced production of $\mathrm{Ca}^{2+}$ in HeLa cells. Cells were treated with $75 \mu \mathrm{M}$ DAS for various time periods before cells were collected, stained by $\mathrm{DiOC}_{6}$ for $\Delta \Psi_{\mathrm{m}}$ levels (A) and by Indo $1 / \mathrm{AM}$ for $\mathrm{Ca}^{2+}$ levels determined (B) as described in Materials and methods. Data represent the mean \pm SD of three experiments. ${ }^{* * *} \mathrm{P}<0.001$.

A

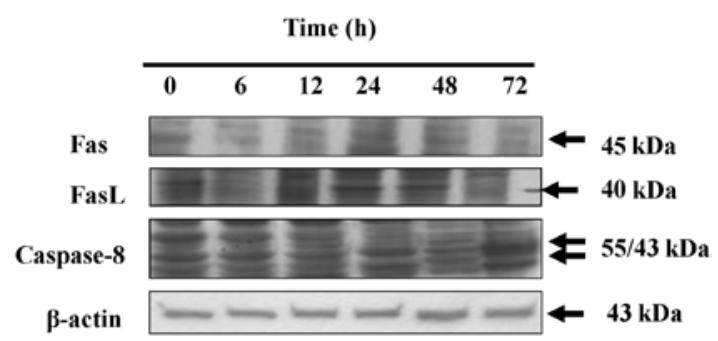

B

Time (h)

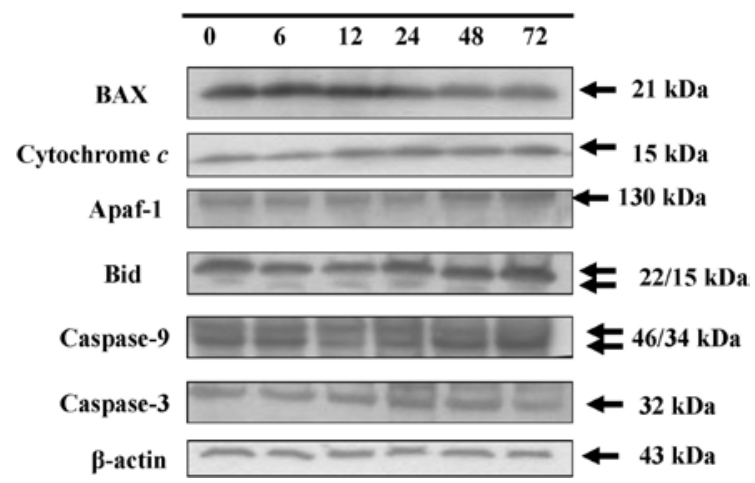

Figure 5. DAS affects the levels of apoptotic associated proteins of HeLa cells. Cells were treated with DAS at $75 \mu \mathrm{M}$ for various time periods before cells were harvested for Western blotting as described in Materials and methods. The associated protein expressions (A, Fas, FAsL and caspase-8; B, Bax, cytochrome c, Apaf-1, Bid, caspase-9 and-3) were estimated by Western blotting, as described in Materials and methods. 
A

Time (h)

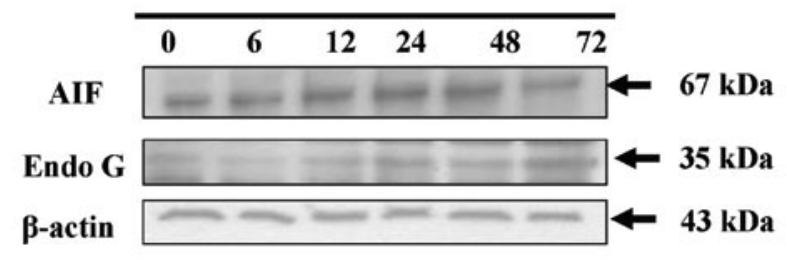

B

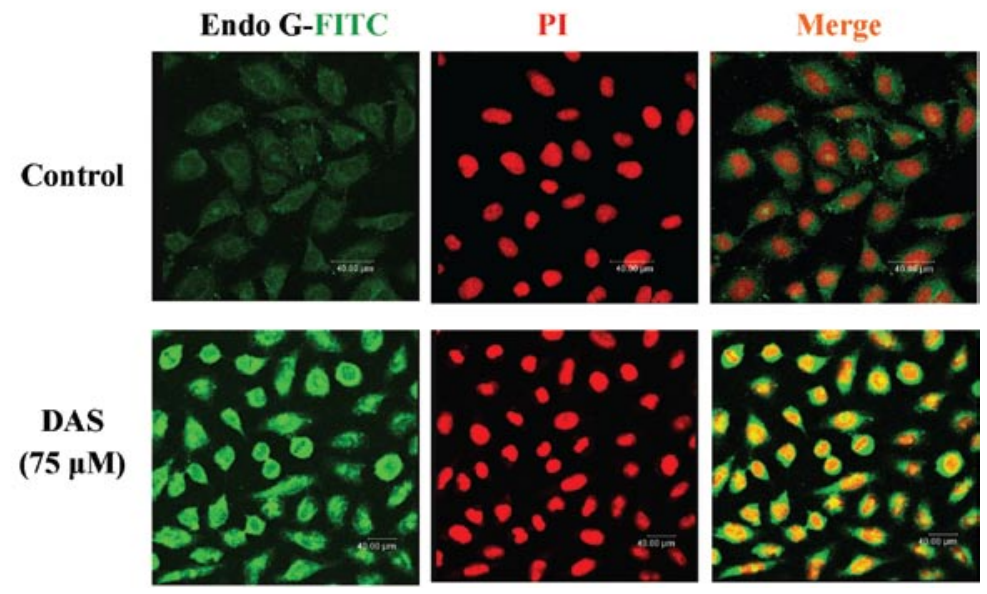

Figure 6. DAS promots the release of AIF and Endo G from mitochondria in HeLa cells. The cells were exposed to $75 \mu \mathrm{M}$ of DAS for $24 \mathrm{~h}$, then either were harvested for Western blotting (A) or were stained and examined and photographed by confocal microscopy (B) and were photographed as described in Materials and methods. Scale bar, $40 \mu \mathrm{m}$.

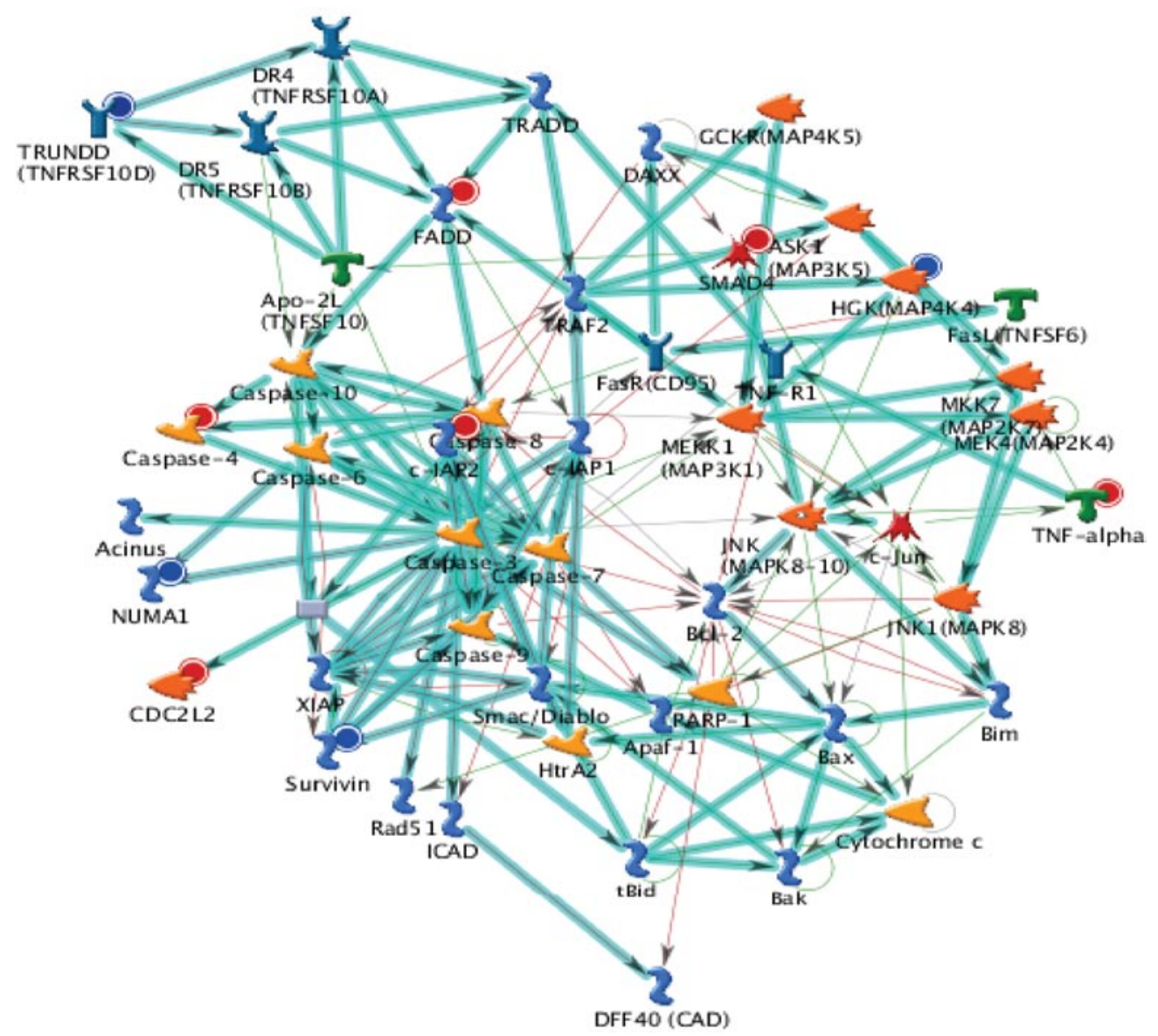

Figure 7. The top scorers by the number of pathways from GeneGo analysis. Thick cyan lines indicate the fragments of canonical pathways. 
Table I. Up- and down-regulated genes.

\begin{tabular}{|c|c|c|}
\hline $\begin{array}{l}\text { Fold } \\
\text { change }\end{array}$ & Gene symbol & mRNA description \\
\hline 2.440 & SNORA62 & Homo sapiens small nucleolar RNA, H/ACA box 62 (SNORA62), non-coding RNA \\
\hline 2.420 & LOC441233 & Homo sapiens cDNA FLJ46129 fis, clone TESTI2046188. \\
\hline 2.399 & ZNF69 & Homo sapiens zinc finger protein 69 (ZNF69), mRNA \\
\hline 2.397 & AKR1C2 & $\begin{array}{l}\text { Homo sapiens aldo-keto reductase family } 1 \text {, member } \mathrm{C} 2 \text { (dihydrodiol dehydrogenase } 2 \text {; bile acid } \\
\text { binding protein; } 3-\alpha \text { hydroxysteroid dehydrogenase, type III) (AKR1C2), transcript variant } 1 \text {, } \\
\text { mRNA }\end{array}$ \\
\hline 2.225 & FOXD1 & Homo sapiens forkhead box D1 (FOXD1), mRNA \\
\hline 2.212 & LOC284861 & Homo sapiens cDNA FLJ46366 fis, clone TESTI4051388 \\
\hline 2.204 & POM121L1P & $\begin{array}{l}\text { Homo sapiens POM121 membrane glycoprotein-like } 1 \text { (rat) pseudogene (POM121L1P), non-coding } \\
\text { RNA }\end{array}$ \\
\hline 2.146 & LIPK & Homo sapiens lipase, family member K (LIPK), mRNA \\
\hline 2.116 & SUMO1P3 & Homo sapiens SUMO1 pseudogene 3 (SUMO1P3), non-coding RNA \\
\hline 2.081 & POM121L2 & POM121-like protein 2 gene:ENSG00000158553 \\
\hline 2.075 & CST1 & Homo sapiens cystatin $\mathrm{SN}$ (CST1), mRNA \\
\hline 2.041 & SAA1 & Homo sapiens serum amyloid A1 (SAA1), transcript variant 1, mRNA \\
\hline 2.023 & KIR2DL3 & $\begin{array}{l}\text { Homo sapiens killer cell immunoglobulin-like receptor, long cytoplasmic tail, } 3 \text { (KIR2DL3), } \\
\text { transcript variant } 1\end{array}$ \\
\hline 2.022 & SSX9 & Homo sapiens synovial sarcoma, X breakpoint 9 (SSX9), mRNA \\
\hline 2.015 & SLFN12L & Homo sapiens schlafen family member 12-like (SLFN12L), mRNA \\
\hline 2.009 & UGT2B28 & Homo sapiens UDP glucuronosyltransferase 2 family, polypeptide B28 (UGT2B28), mRNA \\
\hline-2.015 & SPRR2D & Homo sapiens small proline-rich protein 2D (SPRR2D), mRNA \\
\hline-2.036 & NCRNA00116 & Homo sapiens cDNA clone IMAGE:5763979. \\
\hline-2.109 & B3GALT5 & $\begin{array}{l}\text { Homo sapiens UDP-Gal: } \beta \text { GlcNAc } \beta \text {-1,3-galactosyltransferase, polypeptide } 5 \text { (B3GALT5), transcript } \\
\text { variant } 3\end{array}$ \\
\hline-2.111 & CD209 & Homo sapiens CD209 molecule (CD209), transcript variant 2, transcribed RNA \\
\hline-2.117 & STARD9 & Homo sapiens cDNA FLJ58093 complete cds, highly similar to StAR-related lipid transfer protein 9 \\
\hline-2.185 & PDCD1LG2 & Homo sapiens programmed cell death 1 ligand 2 (PDCD1LG2), mRNA \\
\hline-2.255 & VN1R4 & Homo sapiens vomeronasal 1 receptor 4 (VN1R4), mRNA \\
\hline-2.354 & PSG2 & Homo sapiens pregnancy specific $\beta$-1-glycoprotein 2 (PSG2), mRNA \\
\hline-2.372 & RNU13P2 & Homo sapiens U13 snRNA pseudogene U13.32A \\
\hline-2.612 & LOC201229 & Homo sapiens hypothetical protein LOC201229 (LOC201229), mRNA \\
\hline-2.646 & ROCK1 & Homo sapiens Rho-associated, coiled-coil containing protein kinase 1 \\
\hline
\end{tabular}

at least by 2-fold compared with the untreated control cells. We observed that SNORA62, LOC441233, ZNF69, AKR1C2, FOXD1, LOC284861, POM121L1P, LIPK, SUMO1P3, POM121L2, CST1, SAA1, KIR2DL3, SSX9, SLFN12L and UGT2B28 mRNA were up-regulated and SPRR2D, NCRNA00116, B3GALT5, CD209, STARD9, PDCD1LG2, VN1R4, PSG2, RNU13P2, LOC201229 and ROCK1 mRNA were down-regulated in the DAS-treated cells (Table I). The top scorers by the number of pathways network from GeneGo analysis program is shown in Fig. 7. Thick cyan lines indicate the fragments of canonical pathways. These genes may also be involved in cell cycle arrest and apoptosis, inducing the effect of DAS on HeLa cells.

\section{Discussion}

It is well documented that apoptosis plays an important role in organisms such as for the developmental processes, maintenance of homeostasis, and elimination of the damage cells. Clinical anti-cancer drugs are used for causing cell death by induction of apoptosis in cancer cells $(38,39)$. DAS has been showed to promote immune responses in leukemic mice in vivo (29). However, DAS induces cell apoptosis in cervical cancer is still unclear. Therefore, the purpose of the present study was to clarify the molecular mechanism of DAS underlying human cervical cancer cells (HeLa). We first demonstrated that HeLa cells treated with DAS showed a 


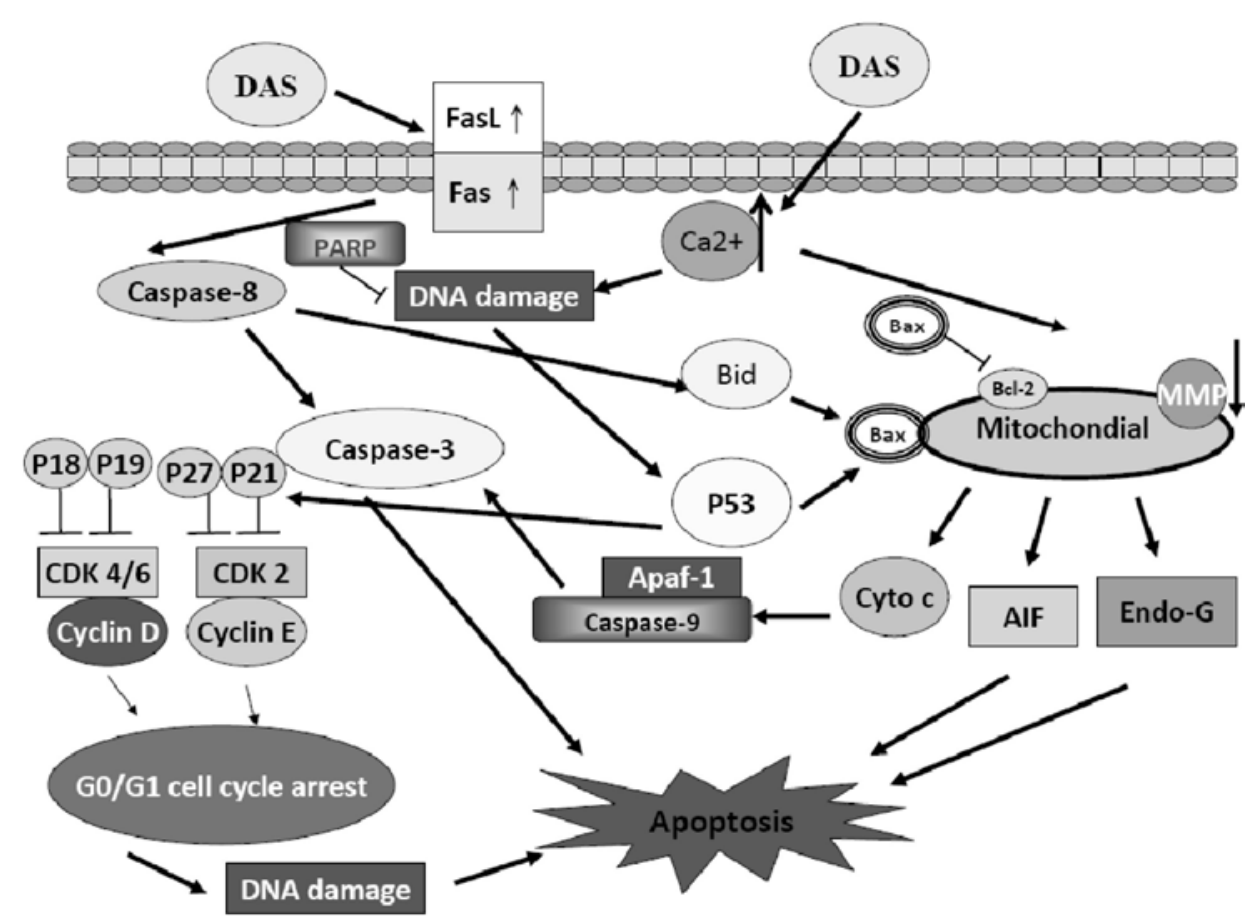

Figure 8. The proposed model of DAS-mediated cell cycle arrest and apoptosis in HeLa cells. DAS induced G0/G1 phase arrest through the Fas and FasL then activated caspase- 8 and -3 or promoted the production of $\mathrm{Ca}^{2+}$ and reduced $\Delta \Psi_{m}$ levels for causing dysfunction of mitochondria then leading to cytochrome $c$, AIF and Endo G release, and promoted caspase-9 and -3 activation causing apoptosis in HeLa cells.

dose- and time-dependent decrease of viable cell number and it also induced morphological changes. DAS also induced apoptosis in HeLa cells based on the observations of nuclear fragmentation (DAPI staining), chromosome condensation, sub-G1 phase of cell cycle and cell shrinkage.

It is known that apoptosis can be through Fas and FasL pathway to activate the caspase- 8 and -3 or through caspase- 8 and mitochondria signaling pathways. Our results from Western blotting showed that DAS promoted the levels of Fas and FasL, caspase- 8 and -3 (Fig. 5). Furthermore, we also showed that DAS decreased the levels of mitochondrial membrane potential and promoted $\mathrm{Ca}^{2+}$ levels in HeLa cells (Fig. 4). Some drugs induced apoptosis via mitochondrion in cancer cells (40). It was reported that the characteristic of mitochondrial death pathway are: i) the changes in the permeability of the outer mitochondrial membrane and ii) the collapse of membrane potential $(41,42)$. Furthermore, mitochondrial membrane permeability has been indicated as controlled by Bax and Bcl-2, both belong to the Bcl-2 family through regulation of the formation of apoptotic proteinconducting pores in the outer mitochondrial membrane $(43,44)$ and at the mitochondrial levels $(45)$.

Our results also showed that DAS promoted the protein levels of cytochrome c, caspase- 9 and -3 and Apaf-1 (Fig. 5B). These observations indicated that DAS promoted the release of cytochrome $\mathrm{c}$ from mitochondria into the cytosol. This is in agreement with other reports showing that the cytosolic cytochrome $\mathrm{c}$ binds to Apaf-1, leading to the activation of caspase-9, -3 and poly(ADP-ribose) polymerase $(46,47)$. Our result clearly demonstrated that DAS induced apoptosis in HeLa cells also through caspase-dependent pathways. It was reported that caspases are integral parts of the apoptotic pathway in response to various stimuli (48). Furthermore, it has been determined that a variety of chemotherapeutic agents induce apoptosis through the activation of caspases (38). Our results showed that DAS promoted the levels of AIF and Endo G in HeLa cells (Fig. 6). It was reported that apoptosis can be induced through caspases-independent pathways, directly through AIF or Endo G release from mitochondria leading to apoptosis (49).

In conclusion, in Fig. 8, we have outlined the molecular mechanism and the overall possible signaling pathways for DAS-induced cell cycle arrest and apoptosis in HeLa cells. According to the present findings, DAS is activated through Fas and FasL then caspase- 8 then caspase- 3 to cause apoptosis, or through increased Bax and Bid, which leads to disruption of mitochondrial membrane potential, and then activates mitochondria-mediated downstream molecular events including cytochrome $\mathrm{c}$ release and sequential activation of caspase- 9 and -3 or through the release of AIF and Endo G causing apoptosis in HeLa cells.

\section{Acknowledgements}

This work was supported by the grant CMU99-TC-15 from China Medical University and the grant NSC96-2815-C-039044-B from National Science Council, Taiwan.

\section{References}

1. Wyllie AH, Kerr JF and Currie AR: Cell death: the significance of apoptosis. Int Rev Cytol 68: 251-306, 1980.

2. Reed JC: Mechanisms of apoptosis. Am J Pathol 157: 1415-1430, 2000.

3. Thornberry NA and Lazebnik Y: Caspases: enemies within. Science 281: 1312-1316, 1998.

4. La Vecchia $C$ and Tavani A: Fruit and vegetables, and human cancer. Eur J Cancer Prev 7: 3-8, 1998. 
5. Rivlin RS: Historical perspective on the use of garlic. J Nutr 131: S951-S954, 2001.

6. Lau BH, Yamasaki T and Gridley DS: Garlic compounds modulate macrophage and T-lymphocyte functions. Mol Biother 3: 103-107, 1991.

7. Lamm DL and Riggs DR: The potential application of Allium sativum (garlic) for the treatment of bladder cancer. Urol Clin North Am 27: 157-162, xi, 2000.

8. Agarwal KC: Therapeutic actions of garlic constituents. Med Res Rev 16: 111-124, 1996.

9. Steiner M and Lin RS: Changes in platelet function and susceptibility of lipoproteins to oxidation associated with administration of aged garlic extract. J Cardiovasc Pharmacol 31: 904-908, 1998

10. Rahman K: Historical perspective on garlic and cardiovascular disease. J Nutr 131: S977-S979, 2001.

11. Steiner M and Li W: Aged garlic extract, a modulator of cardiovascular risk factors: a dose-finding study on the effects of AGE on platelet functions. J Nutr 131: S980-S984, 2001.

12. Sheela CG, Kumud K and Augusti KT: Anti-diabetic effects of onion and garlic sulfoxide amino acids in rats. Planta Med 61: 356-357, 1995

13. Augusti KT and Sheela CG: Antiperoxide effect of S-allyl cysteine sulfoxide, an insulin secretagogue, in diabetic rats. Experientia 52: 115-120, 1996.

14. Cellini L, Di Campli E, Masulli M, Di Bartolomeo S and Allocati N: Inhibition of Helicobacter pylori by garlic extract (Allium sativum). FEMS Immunol Med Microbiol 13: 273-277, 1996.

15. Avato P, Tursil E, Vitali C, Miccolis V and Candido V: Allylsulfide constituents of garlic volatile oil as antimicrobial agents. Phytomedicine 7: 239-243, 2000.

16. Guo NL, Lu DP, Woods GL, et al: Demonstration of the antiviral activity of garlic extract against human cytomegalovirus in vitro. Chin Med J (Engl) 106: 93-96, 1993.

17. Moriguchi T, Saito $\mathrm{H}$ and Nishiyama N: Aged garlic extract prolongs longevity and improves spatial memory deficit in senescence-accelerated mouse. Biol Pharm Bull 19: 305-307, 1996.

18. Nishiyama N, Moriguchi $\mathrm{T}$ and Saito $\mathrm{H}$ : Beneficial effects of aged garlic extract on learning and memory impairment in the senescence-accelerated mouse. Exp Gerontol 32: 149-160, 1997.

19. Yang CS, Chhabra SK, Hong JY and Smith TJ: Mechanisms of inhibition of chemical toxicity and carcinogenesis by diallyl sulfide (DAS) and related compounds from garlic. J Nutr 131: S1041-S1045, 2001.

20. Milner JA: Mechanisms by which garlic and allyl sulfur compounds suppress carcinogen bioactivation. Garlic and carcinogenesis. Adv Exp Med Biol 492: 69-81, 2001.

21. Thomson M and Ali M: Garlic [Allium sativum]: a review of its potential use as an anti-cancer agent. Curr Cancer Drug Targets 3: $67-81,2003$

22. Fleischauer AT and Arab L: Garlic and cancer: a critical review of the epidemiologic literature. J Nutr 131: S1032-S1040, 2001.

23. Herman-Antosiewicz A and Singh SV: Signal transduction pathways leading to cell cycle arrest and apoptosis induction in cancer cells by Allium vegetable-derived organosulfur compounds: a review. Mutat Res 555: 121-131, 2004.

24. Dausch JG and Nixon DW: Garlic: a review of its relationship to malignant disease. Prev Med 19: 346-361, 1990.

25. Chung JG, Chen GW, Wu LT, et al: Effects of garlic compounds diallyl sulfide and diallyl disulfide on arylamine $\mathrm{N}$-acetyltransferase activity in strains of Helicobacter pylori from peptic ulcer patients. Am J Chin Med 26: 353-364, 1998.

26. Chen GW, Chung JG, Ho HC and Lin JG: Effects of the garlic compounds diallyl sulphide and diallyl disulphide on arylamine $\mathrm{N}$-acetyltransferase activity in Klebsiella pneumoniae. J App Toxicol 19: 75-81, 1999.

27. Chen GW, Chung JG, Hsieh CL and Lin JG: Effects of the garlic components diallyl sulfide and diallyl disulfide on arylamine $\mathrm{N}$-acetyltransferase activity in human colon tumour cells. Food Chem Toxicol 36: 761-770, 1998.

28. Chung JG: Effects of garlic components diallyl sulfide and diallyl disulfide on arylamine $\mathrm{N}$-acetyltransferase activity in human bladder tumor cells. Drug Chem Toxicol 22: 343-358, 1999.
29. Yu FS, Wu CC, Chen CT, et al: Diallyl sulfide inhibits murine WEHI-3 leukemia cells in BALB/c mice in vitro and in vivo. Hum Exp Toxicol 28: 785-790, 2009.

30. Lu CC, Yang JS, Huang AC, et al: Chrysophanol induces necrosis through the production of ROS and alteration of ATP levels in J5 human liver cancer cells. Mol Nutr Food Res 54: 967-976, 2010.

31. Chiang JH, Yang JS, Ma CY, et al: Danthron, an anthraquinone derivative, induces DNA damage and caspase cascades-mediated apoptosis in SNU-1 human gastric cancer cells through mitochondrial permeability transition pores and bax-triggered pathways. Chem Res Toxicol (In press).

32. Ji BC, Hsu WH, Yang JS, et al: Gallic acid induces apoptosis via caspase-3 and mitochondrion-dependent pathways in vitro and suppresses lung xenograft tumor growth in vivo. J Agric Food Chem 57: 7596-7604, 2009.

33. Wu SH, Hang LW, Yang JS, et al: Curcumin induces apoptosis in human non-small cell lung cancer NCI-H460 cells through ER stress and caspase cascade- and mitochondria-dependent pathways. Anticancer Res 30: 2125-2133, 2010

34. Ho YT, Lu CC, Yang JS, et al: Berberine induced apoptosis via promoting the expression of caspase- $8,-9$ and -3 , apoptosisinducing factor and endonuclease G in SCC-4 human tongue squamous carcinoma cancer cells. Anticancer Res 29: 4063-4070, 2009.

35. Yang JS, Hour MJ, Huang WW, Lin KL, Kuo SC and Chung JG: MJ-29 inhibits tubulin polymerization, induces mitotic arrest, and triggers apoptosis via cyclin-dependent kinase 1-mediated Bcl-2 phosphorylation in human leukemia U937 cells. J Pharmacol Exp Ther 334: 477-488, 2010.

36. Hsu HY, Yang JS, Lu KW, et al: An experimental study on the antileukemia effects of gypenosides in vitro and in vivo. Integr Cancer Ther (In press).

37. Jacobs AT and Marnett LJ: HSF1-mediated BAG3 expression attenuates apoptosis in 4-hydroxynonenal-treated colon cancer cells via stabilization of anti-apoptotic $\mathrm{Bcl}-2$ proteins. J Biol Chem 284: 9176-9183, 2009.

38. Lah JJ, Cui W and Hu KQ: Effects and mechanisms of silibinin on human hepatoma cell lines. World J Gastroenterol 13: 5299-5305, 2007

39. Edderkaoui M, Odinokova I, Ohno I, et al: Ellagic acid induces apoptosis through inhibition of nuclear factor kappa $B$ in pancreatic cancer cells. World J Gastroenterol 14: 3672-3680, 2008.

40. Liu MJ, Wang Z,Li HX, Wu RC, Liu YZ and Wu QY: Mitochondrial dysfunction as an early event in the process of apoptosis induced by woodfordin I in human leukemia K562 cells. Toxicol Appl Pharmacol 194: 141-155, 2004.

41. Martinou JC and Green DR: Breaking the mitochondrial barrier. Nat Rev Mol Cell Biol 2: 63-67, 2001

42. Wang X: The expanding role of mitochondria in apoptosis. Genes Dev 15: 2922-2933, 2001.

43. Adams JM and Cory S: The Bcl-2 protein family: arbiters of cell survival. Science 281: 1322-1326, 1998.

44. Cory S and Adams JM: The Bcl2 family: regulators of the cellular life-or-death switch. Nat Rev Cancer 2: 647-656, 2002.

45. Cory S, Huang DC and Adams JM: The Bcl-2 family: roles in cell survival and oncogenesis. Oncogene 22: 8590-8607, 2003.

46. Yang J, Liu X, Bhalla K, et al: Prevention of apoptosis by Bcl-2: release of cytochrome $\mathrm{c}$ from mitochondria blocked. Science 275: 1129-1132, 1997.

47. Kluck RM, Bossy-Wetzel E, Green DR and Newmeyer DD: The release of cytochrome $\mathrm{c}$ from mitochondria: a primary site for Bcl-2 regulation of apoptosis. Science 275: 1132-1136, 1997.

48. Tewari M, Quan LT, O'Rourke K, et al: Yama/CPP32 beta, a mammalian homolog of CED-3, is a CrmA-inhibitable protease that cleaves the death substrate poly(ADP-ribose) polymerase. Cell 81: 801-809, 1995.

49. Burz C, Berindan-Neagoe I, Balacescu O and Irimie A Apoptosis in cancer: key molecular signaling pathways and therapy targets. Acta Oncol 48: 811-821, 2009. 